\title{
PHILOLOGY
}

\section{ПАРЕМИЧЕСКИЕ АЛЛЮЗИИ В МУЛЬТИКУЛЬТУРНОМ ХУДОЖЕСТВЕННОМ ДИСКУРСЕ САЛМАНА РУШДИ (НА МАТЕРИАЛЕ POMAHA “THE GROUND BENEATH HER FEET")}

\author{
Ирина Саакян, \\ Аспирант АрГУ, Армения, Степанакерт. \\ DOI: https://doi.org/10.31435/rsglobal_ws/31032019/6416
}

\section{ARTICLE INFO}

Received: 24 January 2019

Accepted: 16 March 2019

Published: 31 March 2019

\section{KEYWORDS}

allusion, paremic allusion,

stylistic convergence,

metaphor,

simile.

\begin{abstract}
The article considers paremic allusions as units with rich cultural semantics, allowing to understand the information of cultural value provided in multicultural artistic discourse. It presents a detailed analysis of the examples of paremic allusions with the description of cases when allusion is combined with metaphor, simile, irony, sarcasm, epithet emphasizing expressive potential of allusive convergence.
\end{abstract}

Citation: Ирина Саакян. (2019) Parmichski Allyuzii v Mul'tikul'turnom Hudozhstvnnom Diskurs Salmana Rushdi (na Matriale Romana "The Ground Beneath Her Feet"). World Science. 3(43), Vol.3. doi: 10.31435/rsglobal_ws/31032019/6416

Copyright: (C) 2019 Ирина Саакян. This is an open-access article distributed under the terms of the Creative Commons Attribution License (CC BY). The use, distribution or reproduction in other forums is permitted, provided the original author(s) or licensor are credited and that the original publication in this journal is cited, in accordance with accepted academic practice. No use, distribution or reproduction is permitted which does not comply with these terms.

Для полного восприятия всех смысловых оттенков мультикультурной природы современной британской литературы, описывающей различные культурные традиции и реалии, изучение лингвокультурологических особенностей аллюзии, обладающей национальнокультурологическим компонентом значения, представляется нам закономерным.

По своей природе аллюзия это ускользающий феномен, имеет риторический характер и зависит от имплицитного понимания автор-читатель, того, что по большей части остается несказанным, кроме следа другого текста на поверхности дискурса (Lennon 2004: 15).

В своей работе «Введение в теорию интертекстуальности» Н. Пьеге-Гро определяет аллюзию как «риторическую фигуру, с помощью которой дают представление о вещи, не называя ее непосредственно; интертекстовая аллюзия заключается в том, чтобы - в имплицитной форме установить связь данного текста с другим текстом» (Пьеге-Гро 2008: 226).

Схожего мнения придерживается и К. Новожилова в учебном пособии «Стилистика повествовательного текста», где дает следующую дефиницию аллюзии: «Аллюзия представляет собой риторическую фигуру, которая отсылает к предметной ситуации других текстов... Аллюзия выражается скрытой, анонимной цитатой и содержит в себе намек на литературный или общекультурный факт, входящий в тезаурус и автора, и читателя» (Новожилова 2007: 84). Аллюзии, как элементы углубляющие смысл высказывания, также строятся на основе широко известных текстов, к которым Г. Пермяков относит пословицы, поговорки, ходячие литературные цитаты и другие клишированные изречения (Пермяков 1971: 48-49). 
Роман британского писателя Салмана Рушди “The Ground Beneath Her Feet”, являющийся ярким примером мультикультурного художественного дискурса ${ }^{1}$, изобилует паремическими аллюзиями, с помощью которых автор описывает события, характеры, поступки своих героев.

Паремическая аллюзия, также, как и фразеологическая аллюзия, определяется как “неявная мысленная ссылка к образу фразеологической единицы, которая представлена в дискурсе одним или двумя эксплицитными компонентами - несущими образ, намекающих на этот образ” (Naciscione 2001: 100). Паремическая аллюзия устанавливает связь между полной формой пословицы и его дискурсивными указателями. Связь устанавливается на основе ключевых элементов лексического уровня пословицы, которые, в идеале, автоматически связаны с пословицей. Часто бывают случаи, когда отдельные лексические единицы могут выступать за целую пословицу.

Примечательно, что сам С. Рушди ясно осознает о существовании связи между формой, которую он использует и текстом источником на который он ссылается, а в некоторых случаях с помощью контекста, очевидным образом, устанавливает провербиальную связь.

Однако для усиления семантического и экспрессивного потенциала аллюзивного слова, С. Рушди использует не просто аллюзию, а приводит еe в сочетании с другими стилистическими приемами, образуя тем самым стилистическую конвергенцию ${ }^{2}$.

Одним из основных стилистических приемов, с которым сочетается аллюзия, является метафора. Рассмотрим пример, где аллюзивно воспроизводится содержание одной из известных пословиц:

Ormus Cama's second full-page press advertisement, What Is the Whole Catastrophe?, in which he publicly expressed his fear that some sort of apocalypse might be imminent, some sort of science fiction encounter between variant and incompatible versions of the world, was the last straw. (426)

Выражение 'was the last straw' является аллюзивной ссылкой на пословицу 'It is the last straw that breaks the camel's back' (Последняя капля переполняет чашу), которая представлена в неполной, усеченной форме. Ключевые компоненты пословицы 'the last straw' передают ее основное значение. Данная ссылка призвана реализовать значение 'run out of patience'. Здесь наряду с аллюзией можно наблюдать стилистический прием метафоры, что позволяет судить о наличие стилистической конвергенции.

В следующем примере:

A warning shot across the bows. A word to the wise. [...] A guest who wishes to remain welcome is not well advised to piss on his host's best rug. (381)

номинальная фраза 'a word to the wise' представляет аллюзию на пословицу 'А word to the wise is sufficient' (Умный понимает с полуслова). Хотя аллюзия представлена в усеченной форме, она довольно эксплицитна из-за непосредственного присутствия ключевых маркеров в тексте. Данная аллюзия актуализирует значения 'hint', 'advice', 'warning'. Далее следует метафорическое выражение 'A guest who wishes to remain welcome is not well advised to piss on his host's best rug' ('Хлеб-соль кушай, а хозяина слушай!') означающее, что гость не должен злоупотреблять гостеприимством хозяина.

Эксплицитное упоминание пословицы содержится и в следующем примере:

You have lived in the wood all your life and so you cannot see the trees. (262)

Данная паремическая аллюзия является ссылкой на пословицу 'Can't see the forest for the trees' или 'Can't see the wood for the trees' (За деревьями леса не видеть) и реализует значение 'to be unable to get a general understanding of a situation due to being worried about the details'. В данном примере аллюзия тесно соседствует с метафорой, что позволяет указывать на наличие стилистической конвергенции.

\footnotetext{
${ }^{1}$ Мультикультурный художественный дискурс - это кросскультурное общение в рамках произведения, созданного писателем мигрантом, сочетающим в себе «культурную эклектику», гибридность. Мультикультурный художественный дискурс возникает в области пересечения двух или более культурных традиций. Он включает в себя различные национально-культурные составляющие [Арутюнян 2015: 11].

2 Конвергенция - это средство усиления выразительности, состоящее в концентрации в каком-либо отдельном месте текста пучка изобразительных и выразительных средств, участвующих в реализации одной и той же стилистической функции [Хазагеров, Ширина 1999: 237]. Основоположником понятия «конвергенция стилистических приемов» является М. Риффатер, называвший конвергенцией «...скопление в одном месте нескольких независимых стилистических приемов» [Риффатер 1980: 88].
} 
Основные компоненты следующего выражения 'glistering garbage for gold' в предложении:

Mistake not flamboyance for genius, or glistering garbage for gold. (232)

воспроизводят ссылку на пословицу 'All that glitters is not gold' (Не все то золото, что блестит). Образность пословицы соответствует метафорическому образу предложения: Рай, один из главных героев романа, в качестве журналиста расследует мошенничество, где масштабы аферы просто непостижимы. Здесь аллюзия составляет часть стилистической конвергенции в сочетании с метафорой и эпитетом.

В следующем отрывке мы рассмотрим два примера:

Yeah. And maybe the moon is made of cheese, Standish surrenders to sarcasm. Hey, look. Up in the sky, above the Pheasantry. Wasn't that a flying pig? (293)

В первом случае ссылка представляет пословицу "Мaybe the moon is made of green cheese" (Луна сделана из зеленого сыра) в ее полной форме, с опущением атрибутивного слова "green". Выражение, как правило, использовалось в качестве примера чрезвычайной доверчивости или чтобы подчеркнуть наивность или легкомыслие некоторых людей.

Во втором случае аллюзия представляет ссылку на пословицы 'Pigs might fly if they had wings' / 'Pigs may fly, but they are unlikely birds' (После дождичка в четверг (никогда) / На свете всякие чудеса случаются / Бывает, что коровы летают).

В тексте метафорическое выражение "a flying pig" используется в значении "smth. impossible, incredible, unlikely’. Неодобрительная коннотация выражений соответствует общему саркастическому тону контекста. В связи с наличием в речи героя сарказма, справедливо говорить о наличие стилистической конвергенции. Таким образом, стилистический прием аллюзии совмещает в себе такие приемы как метафора и сарказм.

Далее С. Рушди использует так называемый паремический парафраз, т. е. формулируя определенную пословицу по-другому, сохраняет метафорический образ:

I opened my mouth; he indicated that I should close it. "Seen and not heard," he stated. “Keep your trap shut is best policy." (70)

Очевидно, что первый пример 'Seen and not heard' представляет усеченную форму содержащую ссылку на пословицу 'Children should be seen and not heard' (Детей должно быть видно, но не слышно). В отличие от многих английских идиом, значение данной пословицы буквальное. Она восходит к религиозным взглядам средневековой культуры и первоначально означала, что молодым женщинам не следует говорить в присутствии взрослых, но позже сюда были включены также все дети. Теперь пословица используется в значении 'children should be quiet and well-behaved'.

Пренебрежительный тон прослеживается и во втором примере: 'Keep your trap shut is best policy'. Паремическая интерпретация выражения структурно и семантически отсылает к пословице 'Honesty is the best policy' (Честность - лучшая политика).

Еще один пример парафраза представлен в следующем аллюзивном обращении:

Don't be fooled by appearances, he greets Ormus, handing him a Scotch and soda without troubling to ask, adding: It's mostly phoney. You'll find I'm pretty much a rogue. (259)

Паремическая аллюзия является упоминанием пословицы 'Appearances are deceptive' / 'Never judge by appearances' (Внешность обманчива) с последующей заменой слова 'deceptive' на другое равноправное по смыслу слово 'to fool', которое также используется в значении 'to deceive', 'to mislead'. Обращение призвано реализовать значения 'jumping to conclusions', 'to have the wrong impression'.

Далее посредством аллюзии автор с сарказмом описывает противоречия реального мира, о том, что вчера было нельзя и плохо, сегодня правильно и хорошо:

Celibacy damages the brain, high-rise buildings bring us closer to God, tests show that a bar of chocolate a day significantly improves children's academic performance, exercise kills, tyranny is just a part of our culture... (352)

Здесь нельзя не заметить ссылку на пословицу 'An apple a day keeps a doctor away' (Кто яблоко в день съедает, у того доктор не бывает.) Использование слова 'chocolate' в номинальной фразе придает саркастический оттенок рассматриваемому выражению. В данном случае саркастический эффект создается в результате замены слова 'apple' на 'chocolate', так как всегда было известно, что сладкое - вредно. Аллюзия присутствует в стилистической конвергенции совместно с сарказмом.

Рассмотрим следующий пример, где аллюзия строится на основе сравнения Рима с Нью-Йорком - аллюзивно названного 'this new Rome':

As for Ormus, at first, upon his helicoptered arrival in Manhattan, he enters a condition of worship, marveling at this new Rome, [] One might suggest simply that Ormus Cama's worship of the 
city has quickly been reciprocated; it has become the city's worship of him. And where this city leads, this Rome, all the world's cities quickly follow. (387)

Ключевые элементы аллюзивного предложения leads' и 'Rome' представляют ссылку на пословицу 'All roads lead to Rome' (Все дороги ведут в Рим). Нью - Йорк, представленный в тексте имплицитно, для Ормуса, главного героя романа, является эпицентром земли, как когда-то был Рим, примеру которому следовали в каждом уголке земли. В данном случае активизируются значения "set an example", "be the subject of emulation", признаки, относящиеся к власти Рима, которую он однажды имел над всем миром и на которую Нью-Йорк претендует сейчас.

Нечасто можно встретить аллюзию, отсылающую на один и тот же текст, смысл которого заключен в нескольких предложениях:

I begged her to desist in future, knowing she would not. "Ma, keep mum." "Silent ice is wholly nice." "Ice cream not youce cream." And, parodying the Kwality brand's famous slogan, "A dream without scream." (56)

Выражения 'Silent ice is wholly nice' и 'A dream without scream' эксплицитно отсылают к пословице 'A silent dream is a pleasant dream' (Мечта, что всем по слуху / Тихая мечта - приятный сон). Иронический оттенок выражения соответствует содержанию контекста, в котором Рай просит свою мать, у которой нет ни малейшего музыкального дара, при приготовлении мороженого, фальшиво не насвистывать. Так, наряду с аллюзией можно наблюдать стилистический прием иронии, что позволяет судить о наличие стилистической конвергенции.

Итак, применительно к паремиологии, аллюзия понимается как ссылка на известную паремиологическую единицу или упоминание части паремии вместо всей единицы. Для Рушди использование паремических аллюзий - это игра с языком и с читателем. Паремии будучи богатые в формулировке и образности, позволяют ему использовать определенные элементы как знаки, которые могут представлять паремии метонимически.

Паремии, включенные в текст, в большинстве своем, представляют известные пословицы, чьи полные формы и единичные элементы не сложно идентифицировать как провербиальные, так как в ментальном лексиконе среднего носителя английского языка они связаны с определенными пословицами. Рушди старается не использовать незнакомые или редко встречающиеся пословицы и поэтому не рискует быть непонятым. Используя аллюзии С. Рушди ожидает от читателя дешифровки скрытого послания. В процессе декодирования аллюзии читатель находит заложенное автором значение, понимание которого зачастую необходимо в осмыслении текста. Хотя некоторые представленные примеры могут быть поняты и без ссылки на пословицы, целостность текста раскрывается только после того, когда аллюзия расшифрована.

Анализ примеров демонстрирует большой выразительный потенциал аллюзивной конвергенции. Аллюзия, как стилистический прием, обладает высоким экспрессивным потенциалом, который усиливается в сочетании с другими стилистическими приемами, составляя часть стилистической конвергенции. Основным приемом, с которым сочетается аллюзия, является метафора, используемая с целью усиления образности (художественнообразного выражения мысли), экспрессивности выражения. Весьма распространенным является употребление аллюзии в сочетании с сарказмом, для передачи отрицательных оценочных значений, а также в сочетании с иронией для достижения более эмоционального эффекта.

\section{REFERENCES}

1. Арутюнян Н. Л. Мультикультурный художественный дискурс Сальмана Рушди // Когниция, коммуникация, дискурс. - 2015. - №11. - С. 8 - 18.

2. Новожилова К. Р. Стилистика повествовательного текста: Теоретические и исторические основы: Учебное пособие. - СПб., 2007. - 100с.

3. Пермяков Г. Л. Паремиологический эксперимент. Материалы для паремиологического минимума. Полторы тысячи русских пословиц, поговорок, загадок, примет и других народных изречений, наиболее распространённых в живой разговорной речи. - М.: Наука, 1971. - 215 с.

4. Пьеге-Гро Н. Введение в теорию интертекстуальности. М.: Издательство ЛКИ, 2008. - 240с.

5. Риффатер М. Критерии стилистического анализа // Новое в зарубежной лингвистике. Вып. IX. Лингвостилистика. - М., 1980. - С. 69-95.

6. Хазагеров Т. Г., Ширина Л.С. Общая риторика: Курс лекций; Словарь риторических приемов / отв. ред. Е.И. Ширяев. - Ростов н/Д., 1999. - 320 с.

7. Lennon P. Allusions in the Press: An Applied Linguistic Study, Walter de Gruyter, 2004 - 297p.

8. Naciscione A. Phraseological Units in Discourse: Towards Applied Stylistics. - Riga: Latvian Academy of Culture, 2001. - 283p.

9. Rushdie S. The Ground Beneath Her Feet. London: Vintage Books. 2000. - 575p. 